\title{
Phenotypic and Genotypic Characteristics of Shiga Toxin- producing Escherichia coli Strains Isolated from Children in São Paulo, Brazil
}

\author{
Beatriz EC Guth/+ , Sônia RTS Ramos*, Aloysio MF Cerqueira***, João RC Andrade**, \\ Tânia AT Gomes
}

\footnotetext{
Departamento de Microbiologia, Imunologia e Parasitologia, Universidade Federal de São Paulo, Escola Paulista de Medicina, Rua Botucatu 862, 04023-062 São Paulo, SP, Brasil *Instituto da Criança, Hospital das Clínicas-USP, São Paulo, SP, Brasil **Disciplina de Microbiologia e Imunologia, Universidade Estadual do Rio de Janeiro, Rio de Janeiro, RJ, Brasil ***Departamento de Microbiologia e Parasitologia, Universidade Federal Fluminense, Niterói, RJ, Brasil
}

The biochemical and serological characteristics, virulence properties, and genetic relatedness of Shiga toxinproducing Escherichia coli (STEC) strains isolated in São Paulo, from April 1989 through March 1990, were determined. This is also the first report on clinic findings of human STEC infections in Brazil. The only three STEC strains identified in that period were lysine decarboxylase negative, belonged to serotype Ol11ac: non-motile, were Stxl producers, carried the eae and ast $A$ genes, and 2 of them also presented the EHEC-hly sequence. The children carrying STEC were all boys, with less than two years old, and had no previous history of hospitalization. None of them presented blood in stools. Vomiting, cough and coryza were the most common clinical manifestations observed. Although the STEC strains were isolated during summer months, and presented similar phenotypic and genotypic characteristics, carbohydrate fermentation patterns and PFGE analysis suggested that these diarrheal episodes were not caused by a single clone.

Key words: Shiga toxin-producing Escherichia coli - serotype O111:NM - virulence factors - clinical manifestations São Paulo - Brazil

Shiga toxin (Stx)-producing Escherichia coli (STEC) strains are important agents of gastrointestinal disease in humans, particularly since such infections may result in a life-threatening complication such as the hemolytic uremic syndrome (HUS) (Karmali 1989, Nataro \& Kaper 1998). While numerous outbreaks have been related to $E$. coli serotype O157:H7, several other STEC serotypes have been associated with human diseases (Nataro \& Kaper 1998). Other non-O157 serogroups frequently associated with pathogenicity include $\mathrm{O} 26, \mathrm{O} 91, \mathrm{O} 103, \mathrm{O} 111$, and $\mathrm{O} 113$ (Paton \& Paton 1998).

The ability of STEC strains to cause severe disease is related to the production of one or more types of Stx (Stx1, Stx2, or variants) (Nataro \& Kaper 1998). Several other additional factors that might contribute to the pathogenicity of STEC have been described. These factors include the enterohemolysin, or enterohemorrhagic E. coli hemolysin (EHEC-Hly), which is a member of the repeat in toxin (RTX) family of pore-forming cytolisins, and intimin, the product of the eae gene that is an outer membrane adhesion molecule involved in the establishment of the attaching and effacing (A/E) lesion (Paton \& Paton 1998).

This work was supported by Financiadora de Estudos e Projetos, Ministério da Ciência e Tecnologia, Programa de Apoio a Núcleos de Excelência.

${ }^{+}$Corresponding author. Fax: +55-11-5571.6504. E-mail:

becguth@ecb.epm.br

Received 11 April 2002

Accepted 12 August 2002
Production of $\mathrm{A} / \mathrm{E}$ lesions may be identified by the the fluorescence actin staining (FAS) test (Nataro \& Kaper 1998). Another putative virulence factor that has been identified in $\mathrm{O} 157: \mathrm{H} 7$ and $\mathrm{O} 26: \mathrm{H} 11$ strains, and in some other STEC serotypes is the enteroaggregative E. coli heat-stable enterotoxin (EAST-1), encoded by ast A (Savarino et al. 1996).

STEC are distributed worldwide, and although most sporadic cases and outbreaks of hemorragic colitis (HC) and HUS have been reported from industrialized nations, human infections associated with STEC strains have also been described in some Latin American countries, including Argentina and Chile (Paton \& Paton 1998). In Brazil, there is currently no nationwide surveillance system for HUS, and among the few studies that searched for STEC in diarrheal disease until the year 1999, only two studies identified such strains. In one of them a single STEC strain was isolated from a 3 months-old child with nonbloody diarrhea (Giraldi et al. 1990), and in the other stx genes were found in E. coli strains of 3 out of $505(0.6 \%)$ diarrheic stool specimens (Gomes et al. 1996).

Since there are very few data regarding the characteristics of human STEC infections in Brazil, the aim of the present study was to determine the biochemical and serological characteristics, virulence properties and genetic relationship of the STEC strains isolated in our community. The clinical signs and symptoms observed in the children carrying these strains are also discussed.

\section{MATERIALS AND METHODS}

Origin of the strains - The STEC strains characterized in the present study carried the stxl sequence and were 
identified among 505 children with bloody and non-bloody acute diarrhea (case patients) and 505 age-matched children (1-4 years old) without any gastrointestinal signs or symptoms during the 30 days before collection (control patients). These children presented to the emergency room of Hospital Infantil Menino Jesus (São Paulo, Brazil) for medical attention (April 1989-March 1990) during a study on the epidemiology of acute diarrhea (Gomes et al. 1996). During that study each fecal specimen was examined by standard procedures (Gomes et al. 1991) for the presence of the following enteropathogens: Shigella spp., Salmonella spp., Yersinia enterocolitica, Aeromonas spp., and Campylobacter spp. Rotavirus and Adenovirus were tested by using an ELISA kit. Additionally, five lactosefermenting and any non-lactose-fermenting colonies with morphological characteristics of E. coli were submitted to hybridization assays with radioactive DNA probes for the identification of enterotoxigenic E. coli (ETEC, LT-I, LT-II, ST-Ip, ST-Ih, and ST-II probes), enteroinvasive $E$. coli (EIEC, INV probe), enteropathogenic E. coli (EAF, $b f p \mathrm{~A}$, and eae probes), and Shiga toxin-producing E. coli (STEC, Stx1 and Stx2 probes) (Maas 1983, Gonçalves et al. 1997).

During the epidemiological survey, one pediatrician interviewed the accompanying adults, obtained informed consent, completed a questionnaire, collected fecal specimens, and examined the children. The occurrence of the following signs and symptoms were evaluated in each of the children: fever $\left(\geq 37.5^{\circ} \mathrm{C}\right.$, axilar temperature), vomiting, dehydration (WHO 1984), abdominal pain, cough, coryza, and blood in stools.

Phenotypic characterization of STEC strains - The isolates carrying the stxl sequence were biochemically confirmed as E. coli by the use of a simplified system as previously described (Gomes et al. 1991). Expression of Stx was tested in cytotoxicity assays on Vero and HeLa cells with bacterial supernatant filtrates obtained from Penassay broth (Antibiotic Medium 3; Difco Laboratories, Detroit, MI) cultures, and by neutralization assays with specific Stx 1 antiserum (Giraldi et al. 1990).

The somatic $(\mathrm{O})$ and flagellar $(\mathrm{H})$ antigens of the strains were determined by standard agglutination assays using O1 to O172 and H1 to H51 antisera (Ewing 1986). Production of enterohemolysin was determined by inoculation of bacterial strains onto blood agar plates containing washed sheep erythrocytes and $10 \mathrm{mM} \mathrm{CaCl}_{2}$, and examination of hemolysis zones after $24 \mathrm{~h}$ of incubation (Beutin et al. 1989). Adherence tests with HeLa and Caco-2 cells grown on coverslips were performed according to Cravioto et al. (1979), except that a $4 \mathrm{~h}$ incubation period was used. For the FAS test (Knutton et al. 1989) HeLa monolayers were fixed with formaldehyde, permeabilized by Triton $\mathrm{X}-100$, treated with fluorescein isothiocyanate (FITC)-labelled phalloidin, and viewed in an fluorescence microscope. The invasive ability of the STEC strains to Caco-2 cells was evaluated by the aminoglycoside exclusion assay (Robbins-Browne \& Bennet-Wood 1992). Briefly, semi confluent monolayers of Caco- 2 cells were infected with approximately $10^{7} \mathrm{CFU}$ and after $3 \mathrm{~h}$ of incubation, the preparations were treated with amicacin $(250 \mu \mathrm{g} / \mathrm{ml})$ for 1 $\mathrm{h}$. The monolayers were then washed, lysed and appro- priate dilutions were plated for viable counts. Identical procedures were used with monolayers not treated with the antibiotic to get the total number of cell-associated bacteria. Invasion was expressed as the percentage of cell-associated bacteria that survived after exposure to aminoglycoside. The invasive index represents the results of at least three independent experiments, and were compared to the results obtained with non-invasive $E$. coli K12 HB101 and E. coli H1/1, E. coli O157:H7 EDL 933 and invasive S. flexneri control strains. In order to evaluate the fermentative pattern of STEC strains, a simplified outline with five carbohydrates: sorbitol, dulcitol, raffinose, sucrose, and rhamnose was used (Camguilhem \& Milon 1989), and the tests were observed for 7 days.

Genotypic characterization of STEC strains - To further characterize the STEC strains, they were tested for the presence of DNA sequences related to EHEC-hly (EHEC probe) and EAST1 (ast A probe) by colony hybridization, as previously described (Gonçalves et al. 1997, Yamamoto \& Nakazawa 1997).

$P F G E$ - To analyse the genetic relationship of the STEC strains, PFGE was performed as described by Pfaller et al. (1994). Digestion was carried out with $20 \mathrm{U}$ of $\mathrm{Xba \textrm {I }}$ at $37^{\circ} \mathrm{C}$ for $18 \mathrm{~h}$. DNA fragments were resolved in $1 \%$ agarose gel in $0.5 \mathrm{X}$ Tris borate EDTA electrophoresis buffer at $13^{\circ} \mathrm{C}$, in a Contour Clamped Homogeneous Electric Field (CHEF) DR-III electrophoresis chamber (Bio-Rad). The running conditions were: $21 \mathrm{~h}, 6 \mathrm{~V} / \mathrm{cm}$, using a switch time of 5-30s. According to criteria of Tenover et al. (1995) strains were considered possibly related when they presented with less than 6 bands differences.

\section{RESULTS}

The biochemical characteristics of the isolates carrying the $s t x l$ sequence showed that they behaved as typical E. coli, except that they were lysine decarboxylase negative and non-motile (NM). All the STEC strains belonged to serogroup O111ac, and expressed Stx1. Furthermore, all strains carried eae and astA, while the EHEChly gene was identified in 2 of them (Table I). Production of enterohemolysin correlated with the hybridization results.

All the STEC strains adhered to the surface of HeLa and Caco- 2 cells in loosen clusters, and were FAS positive. Analysis of the potential to invade Caco- 2 cells demonstrated that except for one non-invasive strain, the two others presented invasive indexes of $1.2 \%$ and $2.8 \%$, while the results obtained with control strains EDL933, $S$. flexneri, non-pathogenic wild type E. coli strain $\mathrm{H} 1 / 1$ and E. coli $\mathrm{K} 12 \mathrm{HB} 101$ were $7.6 \%, 20.1 \%, 0.1 \%$ and $0.04 \%$, respectively (Table I). However, none of the STEC strains presented DNA sequence similarity to the INV probe that identifies enteroinvasive E. coli (EIEC).

A different fermentative pattern was observed in each of the STEC strains (Table I).

The children harbouring STEC strains were boys between 12 to 24 months of age, and the clinical manifestations observed are shown in Table II.

The analysis of genetic similarity showed that the STEC strains studied presented different PFGE profiles after restriction analysis with $\mathrm{Xba \textrm {I }}$ (Figure). 
TABLE I

Serotype, virulence markers and carbohydrate fermentation patterns of Shiga toxin-producing Escherichia coli strains isolated from children with acute diarrhea in São Paulo, Brazil

\begin{tabular}{|c|c|c|c|c|c|c|c|c|c|c|c|}
\hline \multirow[b]{2}{*}{ Strain } & \multirow[b]{2}{*}{ Serotype } & \multirow[b]{2}{*}{ Toxin } & \multirow[b]{2}{*}{ DNA markers } & \multirow[b]{2}{*}{ Adherence $^{a}$} & \multirow[b]{2}{*}{ FAS } & \multirow[b]{2}{*}{$\%$ invasion ${ }^{b}$} & \multicolumn{4}{|c|}{ Fermentation of } & \multirow[b]{2}{*}{ Rha } \\
\hline & & & & & & & Sorb & Dul & Raff & Suc & \\
\hline $1731-3$ & O111ac:NM & Stx1 & stx $x_{1}$ eae EHEC-hly ast $\mathrm{A}$ & + & + & $0.3 \pm 0.3$ & - & + & + & - & + \\
\hline $2781-8$ & O111ac:NM & Stx1 & stx $x_{1}$ eae EHEC-hly ast $\mathrm{A}$ & + & + & $2.8 \pm 2.5$ & + & + & + & - & + \\
\hline $3691-5$ & O111ac:NM & Stx 1 & stx $x_{1}$ eae ast $\mathrm{A}$ & + & + & $1.2 \pm 0.9$ & + & + & + & + & + \\
\hline
\end{tabular}

$a$ : bacteria adhered in loosen clusters to HeLa and Caco- 2 cells; $b$ : \% invasion \pm SD of the control strains: E. coli $\mathrm{H} 1 / 1-0.13 \pm 0.09$; E. coli K12 HB101 - $0.04 \pm 0.02$; EDL933 - 7.6 2 2.0; Shigella flexneri $20.1 \pm 6.5$; NM: non-motile; Sorb: sorbitol; Dul: dulcitol; Raff: raffinose; Suc: sucrose; Rha: rhamnose. All strains were lysine decarboxylase negative.

TABLE II

Period of isolation and age and clinical manifestations of the children with acute diarrhea from whom Shiga toxin-producing Escherichia coli (STEC) strains were isolated

\begin{tabular}{lccccccccc}
\hline \multirow{2}{*}{ Strain } & \begin{tabular}{c} 
Month and \\
\cline { 3 - 10 }
\end{tabular} & $\begin{array}{c}\text { Age } \\
\text { year of isolation }\end{array}$ & Vomiting & Fever & $\begin{array}{c}\text { Abdominal } \\
\text { pain }\end{array}$ & $\begin{array}{c}\text { Blood } \\
\text { in stools }\end{array}$ & Dehydration & Cough & Coryza \\
\hline $1731-3$ & $08 / 1989$ & 14 & + & + & + & - & - & + & + \\
$2781-8$ & $a$ & $10 / 1989$ & 15 & + & + & + & - & - & + \\
$3691-5$ & $12 / 1989$ & 22 & + & - & - & - & - & + & + \\
\hline
\end{tabular}

$a$ : rotavirus detected in association with STEC.

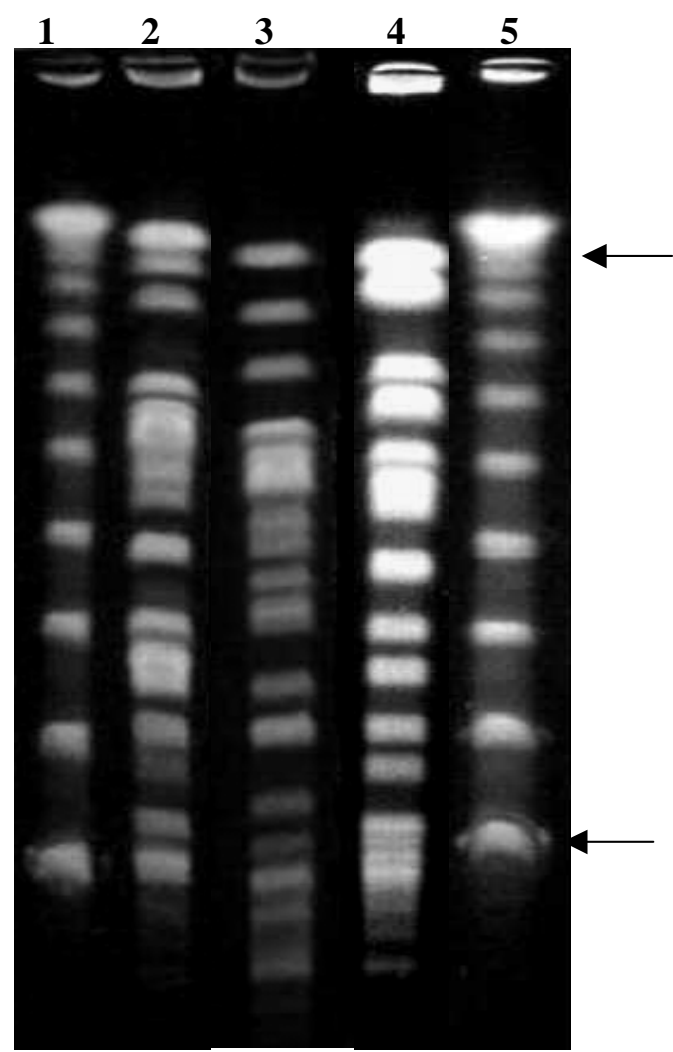

PFGE profiles of Shiga toxin-producing Escherichia coli strains after restriction with $X b a I$. Lanes - 1 and 5: $\lambda$ DNA ladder (the arrows indicate the 48.5 and $485 \mathrm{~kb}$ bands); 2 : 2781-8; 3 : 1731-3; 4 : 3691-5. The figure was generated by the use of Genius Easy Scan/ Color Luxe and digitally processed by Photofinish 3.0 software.

\section{DISCUSSION}

In the present study we described the phenotypic and genotypic characterisitics of STEC strains isolated from diarrheal disease in São Paulo. Moreover, the clinical manifestations of the infections associated with these bacteria and their genetic relationship were also analyzed.

To our knowledge, there are no reports in the literature regarding the occurrence of STEC strains that are devoid of lysine decarboxylase activity. Although with a limited number of strains, it was interesting to observe that the STEC strains of the present study were lysine decarboxylase negative and non-motile; isolates with such characteristics would be classified as non-pathogenic and discarded in a clinical routine analysis in most laboratories in Brazil. These laboratories usually test lysine decarboxylase negative non-motile $E$. coli only with antisera for the EIEC serogroups. This procedure is not correct and should not be performed since it can lead to the lost of important strains as described herein.

The STEC strains belonged to serotype O111ac:NM and although responsible for cases of nonbloody diarrhea, the characterization of virulence markers demonstrated that they were Stx 1 producers, carried the eae and ast $A$ sequences, and 2 of the 3 strains had EHEC- $h l y$ gene.

Data from several studies, have pointed out that the ability to cause attaching and effacing lesions, mediated by the eae gene product intimin, and the expression of EHEC-Hly are the virulence factors most frequently observed, and are commonly harboured by the most virulent STEC strains related to cases of HC and HUS (Paton $\&$ Paton 1998). Although the manner in which this hemol- 
ysin may contribute to the pathogenesis of STEC diseases is not known, Schmidt and Karch (1996), analyzing O111:NM strains, demonstrated a higher frequency of both enterohemolytic phenotype and genotype in STEC strains isolated from patients with HUS than from patients with diarrhea. In this study, two in three of the O111:NM STEC strains had enterohemolytic characteristics, and although no information about the outcome of these patients were available, according to the data from Schmidt and Karch (1996), children with these STEC strains may have had more severe infections.

The role of EAST-1 is still questionable and the significance of the ast A sequence identified in the STEC strains presently studied is unkown. However, as suggested, it may probably be related to the pathogenesis of the watery diarrhea seen in the first stages of STEC infections (Paton \& Paton 1998).

An invasive phenotype to Caco-2 cells was detected in two of the three STEC strains, but with invasion rates lower than those of E. coli $\mathrm{O} 157: \mathrm{H} 7$ and S. flexneri, but significantly higher than that shown by a commensal $E$. coli strain. The clinical significance of this property deserves more studies, but one might suggest that the ability to invade the intestinal epithelium is not an essential STEC virulence attribute, however may be a relevant mechanism in the persistence of the bacteria in the human host and in animal reservoirs.

This is the first study reporting clinic findings of human STEC infections in Brazil, and the clinical manifestations observed were difficult to distinguish from those of infections caused by other enteric pathogens. Although a mixed infection with rotavirus was identified in one child, and rotavirus could possibly be responsible for the symptoms observed in this child, this seems not to be the case since the same symptoms were observed in the other children carrying only STEC. It was also interesting to mention that milder symptoms were observed in the child with the STEC strain devoid of EHEC- $h l y$.

Serotype O111:NM is a well-recognized cause of bloody diarrhea and HUS in different parts of the world (Caprioli \& Tozzi 1998, Banatvala et al. 2001). This serotype was identified in the STEC strains isolated from the children in São Paulo, within a maximum interval of four months, and besides some differences were observed in regard to the fermentative pattern, the different PFGE profiles obtained suggested that the diarrheal episodes associated with these STEC strains were not related to the dissemination of a single clone in our settings.

It should be mentioned that the 3 STEC strains studied herein were included in the clonal analysis of serogroup O111 described by Campos et al (1994). In that previous study by using multilocus enzyme electrophoresis these strains were grouped in ET8, as they carried virulence markers of STEC. However, it was interesting to observe that among the seven strains classified in this ET, three strains did not present any of the typical STEC markers (stx and/or EHEC-hly). In the present study, a better discrimination of the O111:NM STEC strains were obtained by PFGE. In fact, PFGE typing has a higher discriminatory power for STEC strains when compared to other molecular techniques (Martin et al. 1996).
Although the STEC frequency reported in São Paulo is very low, it is comparable to those frequencies obtained in other geographic regions, if only diarrheal cases are analysed (Beutin et al. 1998, Huppertz et al. 1996, Piérard et al. 1997).

More recent studies confirmed that STEC strains are infrequent among children with diarrhea in Brazil (Cantarelli et al. 2000, Irino et al. 2000). However, O157:H7 STEC strains have been, for the first time, reported in association with human disease in our country (Irino et al. 2002), and one HUS case related to O26:H11 STEC infection was also recently identified (Guth et al. 2002). Moreover, serotype O111:NM remains as the most frequent STEC serotype isolated in our settings (Vaz et al., manuscript in preparation). Despite the apparent low occurrence in humans, a high frequency of STEC strains has been found in foods and animal reservoirs (Cerqueira et al. 1997, 1999) but only some of the serotypes identified in animals were recognized as causes of human illness.

Based on these evidences, in summary, O111:NM E. coli represents an important STEC serotype in our community since 1989, and more attention should be payed on the characterization of the virulence markers carried by these strains.

\section{REFERENCES}

Banatvala N, Griffin PM, Greene KD, Barret TJ, Bibb WF, Green JH, Wells JG, Hemolytic Uremic Syndrome Sudy Collaborators 2001. The United States national prospective hemolytic uremic syndrome study: microbiologic, serologic, clinical and epidemiologic findings. J Infect Dis 183: 1063-1070.

Beutin, L, Montenegro MA, Ørskov I, Ørskov F, Prada J, Zimmerman S, Stephan R 1989. Close association of verotoxin (Shiga-like toxin) production with enterohemolysin production in strains of Escherichia coli. J Clin Microbiol 27: 2559-2564.

Beutin L, Zimmerman S, Gleier K 1998. Human infections with Shiga toxin-producing Escherichia coli other than serogroup O157 in Germany. Emerg Infect Dis 4: 635-639.

Camguilhem R, Milon A 1989. Biotypes and O serogroups of Escherichia coli involved in intestinal infections of weaned rabbits: clues to diagnosis of pathogenic strains. J Clin Microbiol 27: 743-747.

Campos LC, Whittam TS, Gomes TAT, Andrade JRC, Trabulsi LR 1994. Escherichia coli serogroup O111 includes several clones of diarrheagenic strains with different virulence properties. Infect Immun 62: 3282-3288.

Cantarelli V, Nagayama K, Takahashi A, Honda T, Cauduro PF, Dias CAG, Mezzari A, Brodt T 2000. Isolation of Shiga toxin-producing Escherichia coli (STEC) serotype O91:H21 from a child with diarrhea in Porto Alegre city, RS, Brazil. Braz J Microbiol 31: 266-270.

Caprioli A, Tozzi AE 1998. Epidemiology of Shiga toxin-producing Escherichia coli infections in Continental Europe. In JB Kaper, AD O'Brien (eds), Escherichia coli O157:H7 and Other Shiga Toxin-producing E. coli Strains, ASM Press, Washington, p. 38-48.

Cerqueira AMF, Guth BEC, Joaquim RM, Andrade JRC 1999. High occurrence of Shiga toxin-producing Escherichia coli (STEC) in healthy cattle at Rio de Janeiro State, Brazil. Vet Microbiol 70: 111-121.

Cerqueira AMF, Tibana A, Guth BEC 1997. High occurrence of Shiga-like-toxin-producing strains among diarrheagenic Escherichia coli isolated from raw beef products in Rio de 
Janeiro City, Brazil. J Food Protect 60: 1-5.

Cravioto A, Gross RJ, Scotland SM, Rowe B 1979. An adhesive factor found in strains of Escherichia coli belonging to the traditional infatile enteropathogenic serotypes. Curr Microbiol 3: 95-99.

Ewing WH 1986. Edwards and Ewing's Identification of Enterobacteriaceae, 4th ed., Elsevier, New York.

Giraldi R, Guth BEC, Trabulsi LR 1990. Production of Shigalike toxin among Escherichia coli strains and other bacteria isolated from diarrhea in São Paulo, Brazil. J Clin Microbiol 28: 1460-1462.

Gomes TAT, Griffin PM, Ivey C, Trabulsi LR, Ramos SRTS 1996. EPEC Infections in São Paulo. Rev Microbiol 27: 2533.

Gomes TAT, Rassi V, Mac Donald KL, Ramos SRTS, Trabulsi LR, Vieira MAM, Guth BEC, Candeias JAN, Ivey C, Toledo MRF, Blake PA 1991. Enteropathogens associated with acute diarrheal disease in urban infants in São Paulo, Brazil. J Infect Dis 164: 331-337.

Gonçalves AG, Campos LC, Gomes TAT, Rodrigues J, Sperandio V, Whittam TS, Trabulsi LR 1997. Virulence properties and clonal structures of strains of Escherichia coli O119 serotypes. Infect Immun 65: 2034-2040.

Guth BEC, Lopes R, Vaz TMI, Irino K 2002. First Shiga toxinproducing Escherichia coli isolate from a patient with hemolytic uremic syndrome in Brazil. Emerg Infect Dis 8: 535-536.

Huppertz HI, Busch D, Schmidt H, Aleksic S, Karch H 1996. Diarrhea in young children associated with Escherichia coli non-O157 organisms that produce Shiga-like toxin. J Pediatr 128: 341-346.

Irino K, Gomes TAT, Vaz TMI, Kano E, Kato MAMF, Dias AMG, Gonçalves CR, Guth BEC 2000. Prevalence of Shiga toxin and intimin gene sequences among Escherichia coli of serogroups O26, O55, O111, O119 and O157 isolated in São Paulo, Brazil. Abstracts of the 4th International Symposium and Workshop on Shiga toxin (Verocytotoxin)-producing Escherichia coli infections. Kyoto, Japan, p. 107.

Irino K, Vaz TMI, Kato MAMF, Naves ZVF, Lara RR, Marco MEC, Rocha MMM, Moreira TP, Gomes TAT, Guth BEC 2002. O157:H7 Shiga toxin-producing Escherichia coli strains associated with sporadic cases of diarrhea in São Paulo, Brazil. Emerg Infect Dis 8: 446-447.

Karmali MA 1989. Infection by verocytotoxin-producing Escherichia coli. Clin Microbiol Rev 2: 15-38.

Knutton S, Baldwin T, Willians H, McNeish AS 1989. Actin accumulation at sites of bacterial adhesion to tissue culture cells: basis of a new diagnostic test for enteropathogenic and enterohemorrhagic Escherichia coli. Infect Immun 57: 1290-1298.

Maas R 1983. An improved colony hybridization method with significantly increase sensitivity for detection of single genes. Plasmid 10: 296-298.

Martin IE, Tyler SD, Tyler KD, Khakhria R, Johnson WM 1996. Evaluation of ribotyping as epidemiological tool for typing Escherichia coli serogroup $\mathrm{O} 157$ isolates. J Clin Microbiol 34: 720-723.

Nataro JP, Kaper JB 1998. Diarrheagenic Escherichia coli. Clin Microbiol Rev 11: 142-201.

Paton JC, Paton AW 1998. Pathogenesis and diagnosis of Shiga toxin-producing Escherichia coli infections. Clin Microbiol Rev 11: 450-479.

Pfaller MA, Hollis RJ, Sader HS 1994. PFGE analysis of chromosomal restriction fragments. In HD Isenberg, Clinical Microbiology Procedures Handbook, Suppl. 1, ASM Press, Washington, p. 10.5.

Piérard D, Stevens D, Moriau L, Lior H, Lauwers S 1997. Isolation and virulence factors of verocytotoxin-producing Escherichia coli in human stool samples. Clin Microbiol Infect 3: 531-539.

Robbins-Browne RM, Bennet-Wood V 1992. Quantitative assessment of the ability of Escherichia coli to invade cultured animal cells. Microb Pathog 12: 159-164.

Savarino SJ, McVeigh A, Watson J, Molina J, Cravioto A, Echeverria P, Bhan MK, Levine MM, Fasano A 1996. Enteroaggregative Escherichia coli heat-stable enterotoxin is not restricted to enteroaggregative Escherichia coli. J Infect Dis 173: 1019-1022.

Schmidt H, Karch H 1996. Enterohemolytic phenotypes and genotypes of Shiga toxin-producing Escherichia coli $\mathrm{O} 111$ strains from patients with diarrhea and hemolytic uremic syndrome. J Clin Microbiol 34: 2364-2367.

Tenover FC, Arbeit RD, Goering RV, Mickelsen PA, Murria BE, Persing DH, Swaminathan B. 1995. Interpreting chromosomal DNA restriction patterns produced by pulsedfield gel electrophoresis: criteria for bacterial strain typing. J Clin Microbol 33: 2233-2239.

WHO 1984. A Manual for the Treatment of Acute Diarrhoea, WHO/ CDD/ SER/ 80, 2nd rev.

Yamamoto T, Nakazawa M 1997. Detection and sequences of the enteroaggregative Escherichia coli heat-stable enterotoxin 1 gene in enterotoxigenic E. coli strains isolated from piglets and calves with diarrhea. J Clin Microbiol 65:34783484 . 